\title{
Effect of Glucose on Endo-xylanase and $\beta$-xylosidase Production by Fungi Isolated in Indonesia
}

\author{
Ririn Krisnawati $^{1} \mathbb{D}$, Sardjono ${ }^{1}$, Jaka Widada ${ }^{2}$, Dian Anggraini Suroto ${ }^{1}(\mathbb{D}$ \\ and Muhammad Nur Cahyanto ${ }^{1 *}$
}

${ }^{1}$ Department of Food and Agricultural Product Technology, Faculty of Agricultural Technology, Universitas Gadjah Mada, Yogyakarta - 55281, Indonesia.

${ }^{2}$ Department of Agricultural Microbiology, Faculty of Agricultural, Universitas Gadjah Mada, Yogyakarta 55281, Indonesia.

\begin{abstract}
Xylanases are widely produced by fungi, and the production of polysaccharide-degrading enzymes, in general, are usually subjected to carbon catabolite repression. In this work, the ability of several Indonesian indigenous fungi to produce endo-xylanase and $\beta$-xylosidase and their responses to glucose as a repressor were determined. Ten fungi were grown in a liquid medium supplemented with glucose as the repressor $(0,1 \%, 3 \%$, and $5 \%)$, and the endo-xylanase and $\beta$-xylosidase productions were assayed. Aspergillus aculeatus FIG1 and $A$. oryzae KKB4 produced 3.85 and $0.70 \mathrm{U} / \mathrm{mL}$ of endoxylanase, respectively, compared with other strains $(0.22 \mathrm{U} / \mathrm{mL}$ or less). Trichoderma asperellum PK1J2, $T$. virens MLT2J2, A. aculeatus FIG1, T. asperellum MLT5J1, A. oryzae KKB4, and $T$. asperellum MLT3J2 produced $0.021-0.065 \mathrm{U} / \mathrm{mL}$ of $\beta$-xylosidase, whereas the other strains produced $0.013 \mathrm{U} / \mathrm{mL}$ or less of $\beta$-xylosidase. Adding $1 \%$ glucose to the growth medium can partially repress endo-xylanase production in A. aculeatus FIG1, T. asperellum PK1J2, and T. virens MLT4J1 and completely repress other strains. By adding 1\% glucose, strains FIG1, PK1J2, and MLT4J1 suffered almost complete repression of $\beta$-xylosidase production, although such strains exhibited partial repression of endo-xylanase production. $\beta$-Xylosidase produced by the other strains showed complete repression by adding $1 \%$ glucose, except for $A$. aculeatus FIG1, A. tamarii FNCC 6151, and T. asperellum MLT1J1, which showed partial repression. Therefore, adding $3 \%$ glucose to the growth medium can result in complete repression of endo-xylanase and $\beta$-xylosidase productions in all strains examined.
\end{abstract}

Keywords: Endo-xylanase, $\beta$-xylosidase, carbon catabolite repression, glucose

\footnotetext{
*Correspondence: mn_cahyanto@ugm.ac.id

(Received: September 19, 2021; accepted: December 3, 2021)

Citation: Krisnawati R, Sardjono, Widada J, Suroto DA, Cahyanto MN. Effect of Glucose on Endo-xylanase and $\beta$-xylosidase Production by Fungi Isolated in Indonesia. J Pure Appl Microbiol. 2022;16(1):226-234. doi: 10.22207/JPAM.16.1.12

(C) The Author(s) 2022. Open Access. This article is distributed under the terms of the Creative Commons Attribution 4.0 International License which permits unrestricted use, sharing, distribution, and reproduction in any medium, provided you give appropriate credit to the original author(s) and the source, provide a link to the Creative Commons license, and indicate if changes were made.
} 


\section{INTRODUCTION}

Xylanases, including hydrolyze xylan to xylose and xylooligosaccharides, are produced by fungi, Actinomycetes, and bacteria. Xylanases are widely used in the food industry, particularly in the production of xylose and xylooligosaccharides, purification of juice and wine, and improvement of dough quality..$^{1-3}$ Hydrolysis of xylan to xylose and xylooligosaccharides can make juice and wine clearer, reduce dough adhesiveness, and increase dough consistency. ${ }^{4,5}$

Filamentous fungi can produce more xylanases than yeast, Actinomycetes, and bacteria. ${ }^{2}$ Filamentous fungi are also more suitable to be used in solid-state fermentation, which can increase the production of enzymes. ${ }^{6}$ Different species of filamentous fungi produce xylanase, such as Aspergillus sp., Trichoderma sp., Penicillium sp., Fusarium sp., and Pseudomonas sp. ${ }^{7}$ Based on previous reports, fungi are good producers of lignocellulolytic enzymes. From an industrial point of view, fungi produce extracellular enzymes that are necessary to hydrolyze lignocellulose materials or several enzymes that are necessary to debranch substituted polysaccharides. ${ }^{8}$ The yield of fungi is also higher than that of yeast and bacteria. Fungi from soil or plants show potential application for xylanase production in industries because they have adapted to hemicellulosic materials.

Although many fungi can produce enzymes at a different level, fungi with different strains could produce different enzymatic activities. A. tubingensis KRCF 700 is the highest cellulase and xylanase producer in CMC and xylan medium among other fungi based on the screening of 16 fungi. $^{9}$ Trichoderma viride Fd18 shows the highest specific xylanase activity of $0.75 \mathrm{U} / \mathrm{mL}$ protein based on microbial screening among soil, decaying wood logs, and sawdust. ${ }^{10}$ Pseudodaphnella stipata SC 04 and Botryosphaeria sp. AM 01 are good producers of xylanase and $\beta$-xylosidase with enzymatic activity of 694.33 and $4.87 \mathrm{U} / \mathrm{g} .{ }^{11}$ The selection of a particular strain to obtain a high enzyme yield must be achieved. Therefore, screening indigenous fungi is important to determine efficient fungi that can produce endo-xylanase and $\beta$-xylosidase.

However, the use of fungi to produce hydrolytic enzymes is hindered by the presence of carbon catabolite repression (CCR), which is a mechanism that regulates gene expression by using a compound that can be easily metabolized as a carbon source. Carbon catabolite repression switches off certain enzymes required to utilize less favored carbon sources when a more readily available carbon source is present in the medium. ${ }^{12}$ Other research has reported that the presence of glucose in the medium induces the growth of fungi, which causes high secretion of enzymes. Therefore, elevated glucose concentration increases amylase production. ${ }^{13}$ In addition, the presence of glucose, sucrose, and galacturonic acid in the medium containing pectin does not reduce pectinase activity. ${ }^{14}$ However, the addition of glucose to the liquid medium increases tannase activity at concentrations of $6.25-25 \mathrm{~g} / \mathrm{L}$ but decreases the enzymatic activity when glucose concentration reaches $50 \mathrm{~g} / \mathrm{L} .{ }^{15}$ Based on the different responses to the presence of glucose, the effect of glucose on endo-xylanase and $\beta$-xylosidase in our isolates must be examined.

Table 1. Fungi used in this study and its origin

\begin{tabular}{lcc}
\hline Fungi & Origin & Accession Number \\
\hline Aspergillus aculeatus FIG1 & Cacao pod, Gunung Kidul & OK336358 \\
Aspergillus oryzae KKB4 & Koji, Kebumen & OK336357 \\
Aspergillus tamarii FNCC 6151 & Koji, Bantul & OK336356 \\
Penicillium citrinum G2J2 & Oil palm empty fruit bunch, Garut & OK336360 \\
Trichoderma asperellum PK1J2 & Oil palm empty fruit bunch, Pekanbaru & OK336355 \\
Trichoderma asperellum MLT1J1 & Coconut husk, Central Maluku & OK336350 \\
Trichoderma virens MLT2J2 & Coconut husk, Central Maluku & OK336351 \\
Trichoderma asperellum MLT3J2 & Coconut stalk, Central Maluku & OK336352 \\
Trichoderma virens MLT4J1 & Coconut rotten wood, Central Maluku & OK336353 \\
Trichoderma asperellum MLT5J1 & Soil, Central Maluku & OK336354 \\
\hline Journal of Pure and Applied Microbiology & 227 & www.microbiologyjournal.org
\end{tabular}


In this study, fungi isolated from various sources in Indonesia were examined for their ability to produce endo-xylanase and $\beta$-xylosidase, and the presence of CCR was observed by adding glucose as a readily metabolized carbon source for the production of enzymes.

\section{MATERIALS AND METHODS Microorganisms}

The fungal strains used in this study were provided by the Biotechnology Laboratory at the Department of Food and Agricultural Product Technology, Gadjah Mada University. The strains were isolated from various sources in Indonesia. Such strains are shown in Table 1. The strains were kept on a potato dextrose agar slant at $4{ }^{\circ} \mathrm{C}$.

Screening of xylanase-producing fungi in a solid medium

The fungi were grown at $30{ }^{\circ} \mathrm{C}$ for 4 days in a solid medium as described by Mandels and Reese ${ }^{16}$, which has been modified by Chand et al. $^{17}$ The medium consisted of urea $(0.3 \mathrm{~g} / \mathrm{L})$, $\left(\mathrm{NH}_{4}\right)_{2} \mathrm{SO}_{4}(1.4 \mathrm{~g} / \mathrm{L}), \mathrm{KH}_{2} \mathrm{PO}_{4}(2.0 \mathrm{~g} / \mathrm{L}), \mathrm{CaCl}_{2} .2 \mathrm{H}_{2} \mathrm{O}$ $(0.4 \mathrm{~g} / \mathrm{L}), \mathrm{MgSO}_{4} .7 \mathrm{H}_{2} \mathrm{O}(0.3 \mathrm{~g} / \mathrm{L})$, peptone (1.0 $\mathrm{g} / \mathrm{L})$, tween $(800.2 \mathrm{~g} / \mathrm{L})$, $\mathrm{FeSO}_{4} .7 \mathrm{H}_{2} \mathrm{O}(5.0 \mathrm{mg} / \mathrm{L})$, $\mathrm{MnSO}_{4} \cdot 7 \mathrm{H}_{2} \mathrm{O}(1.6 \mathrm{mg} / \mathrm{L}), \mathrm{ZnSO}_{4} .7 \mathrm{H}_{2} \mathrm{O}(1.4 \mathrm{mg} / \mathrm{L})$, $\mathrm{CoCl}_{2} .6 \mathrm{H}_{2} \mathrm{O}(20.0 \mathrm{mg} / \mathrm{L})$, agar $(17.5 \mathrm{~g} / \mathrm{L})$, and $0.1 \%$ Triton X-100. The carbon source used was xylan at $10.0 \mathrm{~g} / \mathrm{L}$. The $\mathrm{pH}$ of the medium was adjusted to 5.0. Then, the medium plates were stained using $0.1 \%$ of Congo red and incubated for $20 \mathrm{~min}$. After washing with $1 \mathrm{M} \mathrm{NaCl}$, the diameter of clear zones formed was measured. The xylanolytic activity of the strains was estimated by using a clear zone ratio. ${ }^{6,17}$

Clear zone ratio=(Clear zone diamaterColony diameter)/(Colony diameter)

Xylanase production in liquid culture

The fungi were grown in a liquid medium at $30^{\circ} \mathrm{C}$ for 4 days. The medium used was identical to the solid medium except for agar and Triton $\mathrm{X}-100$, which were omitted from the medium. The broth was centrifuged at $10.000 \mathrm{rpm}$ at $4^{\circ} \mathrm{C}$ for 10 $\mathrm{min}$. The cell-free supernatant was used as a crude enzyme, and its endo-xylanase and $\beta$-xylosidase activities were analyzed.

Effect of glucose on endo-xylanase and $\beta$-xylosidase production

The fungi were grown in a liquid medium supplemented with various amounts of glucose
$(1 \%, 3 \%$, and $5 \%)$ at $30{ }^{\circ} \mathrm{C}$ for 4 days. After incubation, the endo-xylanase and $\beta$-xylosidase activities in the cell-free supernatant were analyzed.

\section{Analysis of endo-xylanase activity}

Analysis of endo-xylanase activity was conducted using the XYIX 6 method from Megazyme Ltd., Ireland, according to the manufacturer's instructions. The substrate used in the assay was xylohexoside, which was blocked at the non-reducing end, and a nitrophenyl moiety was added at the other end. The action of endoglucanase generated a non-blocked xylooligosaccharide that was rapidly hydrolyzed by $\beta$-xylosidase, which was included in the substrate. The 4-nitrophenol formed was measured at 400 $\mathrm{nm}$. One unit of endo-xylanase was defined as the amount of enzyme required to release $1 \mu \mathrm{mol}$ of 4-nitrophenol in $1 \mathrm{~min}$.

\section{Analysis of $\beta$-xylosidase activity}

The $\beta$-xylosidase activity was measured following the methods of Kundu et al. ${ }^{18} \mathrm{~A}$ sample containing $\beta$-xylosidase was added to p-nitrophenyl $\beta$-D-xylopyranoside (Megazyme) as a substrate and incubated for $15 \mathrm{~min}$ at $55^{\circ} \mathrm{C}$. The reaction was ended by adding sodium carbonate as a stopping reagent, and the $p$-nitrophenol formed at $405 \mathrm{~nm}$ was measured. One unit $\beta$-xylosidase activity was defined as the amount of enzyme required to release $1 \mu \mathrm{mol}$ of 4-nitrophenol in 1 min under the defined assay condition. ${ }^{18}$

\section{Statistical analysis}

The statistically treated data were presented as the arithmetical mean values and their standard errors. Data were analyzed using one-way analysis of variance, and differences among means were compared using the Duncan test $(\alpha=0.05)$.

\section{RESULTS AND DISCUSSION Xylanase production}

The fungal strains that produce xylanases were initially screened by observing the clear zones surrounding the colonies in the plate medium after staining with Congo red. All strains examined showed clear zones surrounding the colonies, which indicated that the strains produced xylanases. The size of the clear zone was expressed as the ratio among different clear zones, colony diameters, and colony diameter. A clear zone ratio 
equals to zero indicated no clear zone. The clear zone ratio of each strain varied from 0.36 to 1.02 (Table 2). Among the strains, FIG1, KKB4, FNCC $6151, \mathrm{G} 2 \mathrm{~J} 2$, and MLT4J1 had the highest clear zone ratios.

All strains examined produced endoxylanase and $\beta$-xylosidase in a liquid medium (Table 3). Strain FIG1 produced $3.85 \mathrm{U} / \mathrm{mL}$ of endo-xylanase after 4 days. This amount was considerably higher than that of endo-xylanase produced by the other strains, which was between 0.02 and $0.70 \mathrm{U} / \mathrm{mL}$. Strain KKB4 produced a moderate amount of endo-xylanase, which was $0.70 \mathrm{U} / \mathrm{mL}$, and the rest of the strains produced $0.22 \mathrm{U} / \mathrm{mL}$ or less of endo-xylanase. To date, no report on endo-xylanase production by

Table 2. Clear zone ratio of indigenous strains in xylan agar incubated for 4 days

\begin{tabular}{lc}
\hline Fungi & Clear zone ratio \\
\hline Aspergillus aculeatus FIG1 & $0.96 \pm 0.31^{\mathrm{bcd}}$ \\
Aspergillus oryzae KKB4 & $0.75 \pm 0.35^{\mathrm{bcd}}$ \\
Aspergillus tamarii FNCC 6151 & $0.86 \pm 0.20^{\mathrm{bcd}}$ \\
Penicillium citrinum G2J2 & $0.83 \pm 0.07^{\mathrm{bc}}$ \\
Trichoderma asperellum PK1J2 & $0.59 \pm 0.09^{\mathrm{bc}}$ \\
Trichoderma asperellum MLT1J1 & $0.61 \pm 0.00^{\mathrm{bc}}$ \\
Trichoderma virens MLT2J2 & $0.65 \pm 0.03^{\mathrm{bcd}}$ \\
Trichoderma asperellum MLT3J2 & $0.36 \pm 0.23^{\mathrm{ab}}$ \\
Trichoderma virens MLT4J1 & $1.02 \pm 0.39^{\mathrm{c}}$ \\
Trichoderma asperellum MLT5J1 & $0.53 \pm 0.19^{\mathrm{abc}}$ \\
\hline
\end{tabular}

*Each value is a mean of two replicates; \pm stands for standard deviation among replicates; alphabet means followed by different letters within a column differ significantly at $\alpha \leq 0.05$ microorganisms has been found. Most reports on xylanase production analyzed the enzyme as total xylanase. Researchers used xylan as a substrate and measured the reducing sugars as the product of hydrolysis. Xylanase production measured as total xylanases was reported by workers. A. niger NBRC 31125, A. tubingensis KRCF 700, Grammothele fuligo WD 844, Perenniporia fraxinea WD 1518, Phanerochaete chrysosporium WD 1416, Pycnoporus coccineus WD 2263, $T$. harzianum KRCF 131, T. reesei NBRC 31329, and Trichoderma sp. (four strains) produced xylanase between 0.87 and $7.00 \mathrm{U} / \mathrm{mL} .{ }^{9}$ Another study reported that 50 fungal strains were screened for xylanase production and found that the xylanase production of the top 10 isolates was between 6.43 and $38.90 \mathrm{U} / \mathrm{mL}^{19}$

Among the 10 strains examined, the strain that produced the highest amount of endoxylanase did not produce the highest amount of $\beta$-xylosidase. Strain FIG1 was the highest producer of endo-xylanase, whereas strain PK1J2 was the highest producer of $\beta$-xylosidase, which produced $0.065 \mathrm{U} / \mathrm{mL}$ of $\beta$-xylosidase. Strains MLT2J2, FIG1, MLT5J1, KKB4, and MLT3J2 produced $\beta$-xylosidase between 0.021 and $0.036 \mathrm{U} / \mathrm{mL}$, and the rest of the strains produced only 0.002 to $0.013 \mathrm{U} /$ $\mathrm{mL}$ of $\beta$-xylosidase. Strains FIG1 and KKB4 were considered as high producers of endo-xylanase and $\beta$-xylosidase; they produced 3.85 and $0.70 \mathrm{U} / \mathrm{mL}$ of endo-xylanase, respectively, and 0.031 and 0.021 of $\beta$-xylosidase, respectively. However, the other strains produced a relatively high amount of endoxylanase but a low amount of $\beta$-xylosidase or vice

Table 3. Production of endo-xylanase and $\beta$-xylosidase of indigenous strains in a xylan medium incubated for 4 days

\begin{tabular}{lcc}
\hline Fungi & Endo-xylanase $(\mathrm{U} / \mathrm{mL})$ & $\beta$-xylosidase $(\mathrm{U} / \mathrm{mL})$ \\
\hline Aspergillus aculeatus FIG1 & $3.85 \pm 1.06^{\mathrm{a}}$ & $0.031 \pm 0.001^{\mathrm{a}}$ \\
Aspergillus oryzae KKB4 & $0.70 \pm 0.06^{\mathrm{b}}$ & $0.021 \pm 0.001^{\mathrm{d}}$ \\
Aspergillus tamarii FNCC 6151 & $0.22 \pm 0.02^{\mathrm{b}}$ & $0.002 \pm 0.001^{\mathrm{e}}$ \\
Penicillium citrinum G2J2 & $0.11 \pm 0.02^{\mathrm{b}}$ & $0.005 \pm 0.002^{\mathrm{e}}$ \\
Trichoderma asperellum PK1J2 & $0.06 \pm 0.00^{\mathrm{b}}$ & $0.065 \pm 0.006^{\mathrm{b}}$ \\
Trichoderma asperellum MLT1J1 & $0.10 \pm 0.00^{\mathrm{b}}$ & $0.013 \pm 0.004^{\mathrm{d}}$ \\
Trichoderma virens MLT2J2 & $0.16 \pm 0.02^{\mathrm{b}}$ & $0.036 \pm 0.001^{\mathrm{c}}$ \\
Trichoderma asperellum MLT3J2 & $0.11 \pm 0.03^{\mathrm{b}}$ & $0.021 \pm 0.003^{\mathrm{d}}$ \\
Trichoderma virens MLT4J1 & $0.02 \pm 0.00^{\mathrm{b}}$ & $0.004 \pm 0.002^{\mathrm{e}}$ \\
Trichoderma asperellum MLT5J1 & $0.16 \pm 0.02^{\mathrm{b}}$ & $0.023 \pm 0.000^{\mathrm{d}}$ \\
\hline
\end{tabular}

*Each value is a mean of two replicates; \pm stands for standard deviation among replicates; alphabet means followed by different letters within a column differ significantly at $\alpha \leq 0.05$ 
versa. Previous studies on $\beta$-xylosidase reported that the $\beta$-xylosidase production of four species of Aspergillus was between 0.017 and $0.149 \mathrm{U} /$ $\mathrm{mL} .{ }^{20}$ Other works reported that 12 species of Aspergillus, Beauveria, Mucor, Paecilomyces, and Penicillium were examined for their ability to produce $\beta$-xylosidase and showed that such strains produced $0.030-0.723$ of $\beta$-xylosidase. ${ }^{21}$ Another research reported that $T$. asperellum produced $0.19 \mathrm{U} / \mathrm{mL}$ of $\beta$-xylosidase. ${ }^{22}$

All fungi examined the produced endoxylanase, which was considerably higher than $\beta$-xylosidase. All previous works reported similar results. The strains produced more endo-xylanase than $\beta$-xylosidase. The hydrolysis of xylan to xylose might require more endo-enzyme that cleavages the polymer formed inside than $\beta$-xylosidase, which cut the xylooligosaccharide produced by hydrolyzing endo-xylanase to xylose.
The strains that provided high clear zone ratios did not produce a high amount of xylanase in the liquid medium (Tables 2 and 3). Among the strains that produced high clear zone ratios, T. virens MLT4J1, A. tamarii FNCC 6151, and $P$. citrinum G2J2 produced only $0.02,0.22$, and $0.11 \mathrm{U} / \mathrm{mL}$ of endo-xylanase, respectively, and no $\beta$-xylosidase. However, $A$. aculeatus FIG1 and $A$. oryzae KKB4 were considered as high producers of xylanases in solid and liquid media. In contrast, strains FIG1 and KKB4 produced 3.85 and $0.70 \mathrm{U} /$ $\mathrm{mL}$ of endo-xylanase, respectively, and 0.03 and $0.02 \mathrm{U} / \mathrm{mL}$ of $\beta$-xylosidase, respectively. The other strains examined produced significantly less endoxylanase and $\beta$-xylosidase than strains FIG1 and KKB4 in a liquid medium.

Effect of glucose on the production of endoxylanase and $\beta$-xylosidase

Xylanases are subjected to CCR, where xylose, glucose, or other sugar can repress the

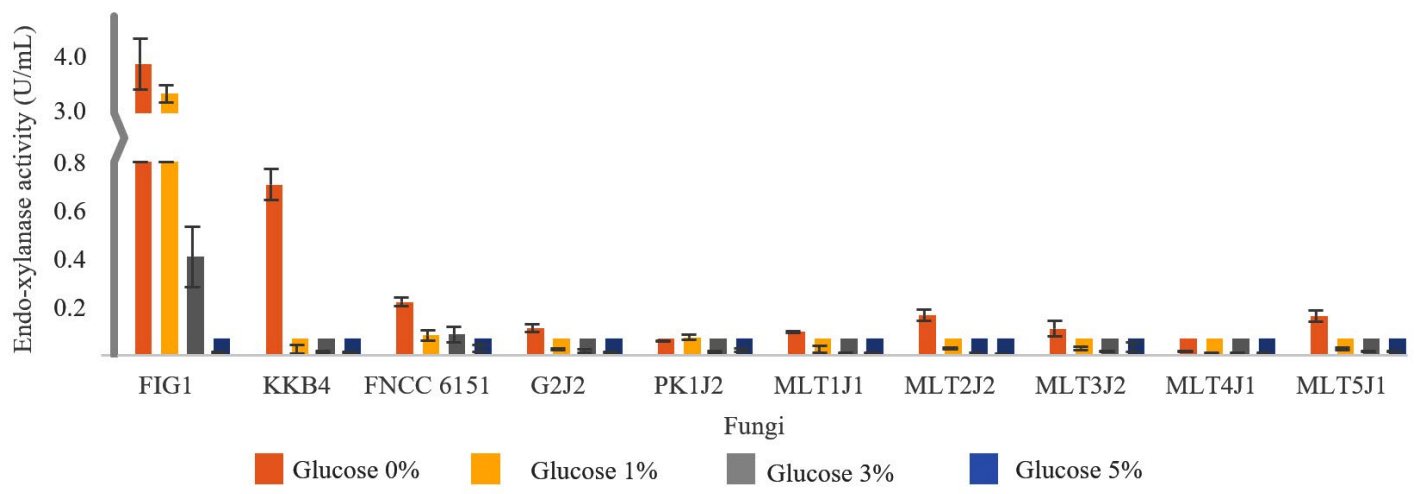

Fig. 1. Endo-xylanase production after the strains were grown in a medium supplemented with various amounts of glucose for 4 days.

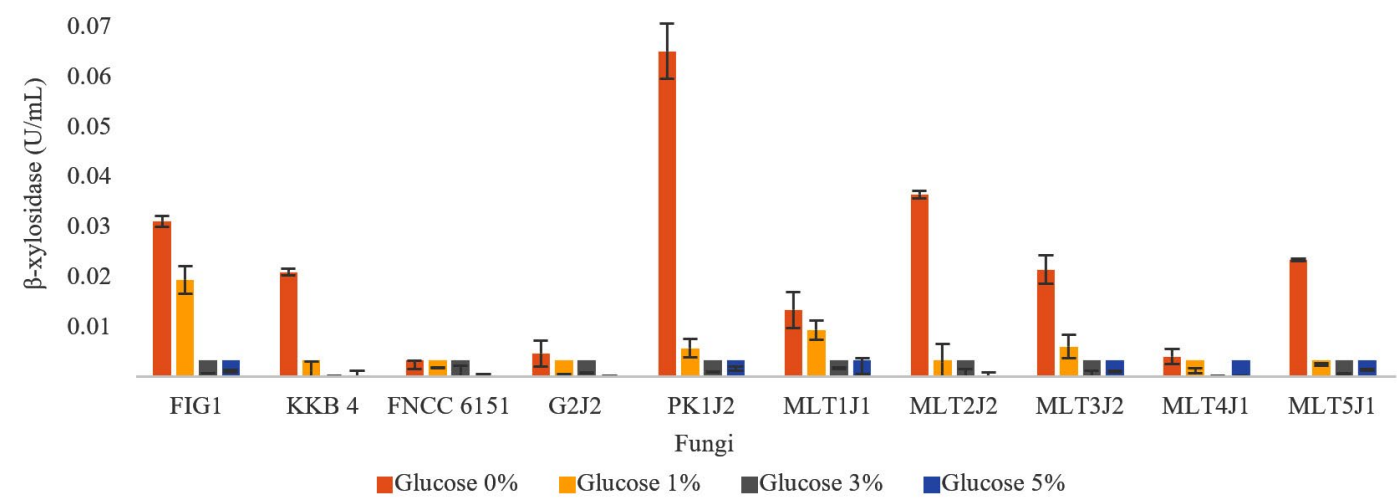

Fig. 2. $\beta$-Xylosidase production after the strains were grown in a medium supplemented with various amounts of glucose for 4 days. 
synthesis of xylanases. In this study, the production of endo-xylanase and $\beta$-xylosidase was examined to determine whether it was affected by the presence of glucose as a readily metabolized sugar in the medium.

As shown in Fig. 1, the addition of glucose significantly decreased the production of endoxylanase. The addition of $1 \%$ glucose to the growth medium decreased the endo-xylanase production by less than $50 \%$ in strains FIG1, PK1J2, and MLT4J1 and by more than $95 \%$ in strain KKB4. Meanwhile, strains FNCC 6151, G2J2, MLT1J1, MLT2J2, MLT3J2, and MLT5J1 decreased the endo-xylanase production from $63 \%$ to $84 \%$ when $1 \%$ glucose was added in the medium. The degree of repression of the production of endo-xylanase after adding 3\% glucose was not significantly different from that after adding $5 \%$ glucose. In general, the production of endo-xylanase in the presence of $3 \%$ glucose or more in all strains was low.

The production of $\beta$-xylosidase in all strains was repressed when the growth medium was supplemented with glucose. In strains FIG1, FNCC 6151, and MLT1J1, the addition of $1 \%$ glucose to the growth medium decreased the $\beta$-xylosidase production by less than $50 \%$. By contrast, the $\beta$-xylosidase production in strains KKB4, G2J2, PK1J2, MLT2J2, and MLT5J1 decreased by $90 \%$ or more when $1 \%$ glucose was added. Meanwhile, the addition of $1 \%$ glucose to the medium decreased $\beta$-xylosidase production by $72 \%-89 \%$ in strains MLT3J2 and MLT4J1. The addition of 3\% glucose or more to the growth medium slightly decreased the $\beta$-xylosidase production in all strains examined, as shown in Fig. 2.

The presence of CCR in endo-xylanase and $\beta$-xylosidase production was observed in $A$. nidulans, $A$. versicolor, and Streptomyces. ${ }^{23-25}$ The presence of $1 \%$ glucose in the medium drastically decreased $\beta$-xylosidase production by $91.82 \%$ in A. versicolor after incubation for $72 \mathrm{~h} .{ }^{24} \mathrm{~A}$ similar result showed that the addition of $1 \%$ glucose to the culture medium of $A$. nidulan slightly inhibited the production of xylanase; however, the activity of xylanase started to be detected after $24 \mathrm{~h}$ when glucose concentration dropped to almost zero. Therefore, $A$. nidulan initially consumed glucose as a carbon source and then the products of xylan hydrolysis when the amount of glucose in the medium was closed to zero. ${ }^{23}$ The addition of glucose, glycerol, and succinic acid in the culture medium individually at $1 \%$ increased the number of carbon sources that strongly repressed endo-xylanase and $\beta$-xylosidase production in Streptomyces. The addition of $1 \%$ xylose to the culture medium reduced the production of endoxylanase and $\beta$-xylosidase in Streptomyces by $81.7 \%$ and $65.1 \%$, respectively. ${ }^{25}$

A. aculeatus FIG1 could be used for endo-xylanase and $\beta$-xylosidase production. Endo-xylanase is an important enzyme in the production of xylooligosaccharides. ${ }^{26,27}$ and it is

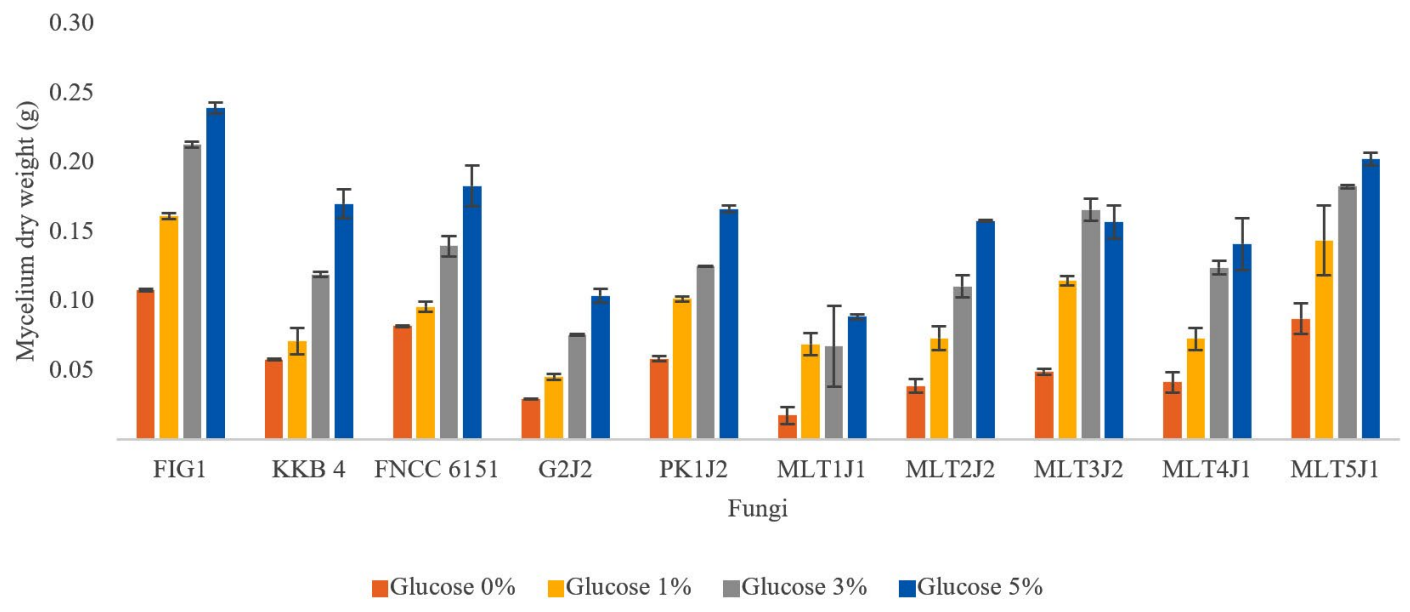

Fig. 3. Biomass produced after the strains were grown in a medium supplemented with various amounts of glucose for 4 days. 
a major prebiotic used as a food ingredient. ${ }^{28,29}$ The substrate used in commercial endo-xylanase production should be the cheap sources of xylan such as corn cob, cane bagasse, and oil palm empty fruit bunch. ${ }^{30,31}$ However, those materials contain a great amount of cellulose, which may be converted into glucose in the presence of cellulases. Most of the xylanase producers exhibit the secretion of cellulases. ${ }^{11,32,33}$ The action of cellulases on cellulose produces glucose, which is readily consumed by the strain. Consequently, the accumulation of xylose in the medium represses the production of endo-xylanase. Therefore, the elimination of CCR in the strain used for commercial production of cellulases is necessary. The repression of hydrolase enzymes in fungi might be related to a regulatory gene, such as creA or cre1. ${ }^{34-36}$ In addition, deletion of creA in A. oryzae RIB40 increased the production of $\alpha$-amylase in a liquid medium containing $1 \%$ glucose from less than 100 $\mathrm{U} / \mathrm{g}$ dry weight in wild type to more than 1.100 $\mathrm{U} / \mathrm{g}$ dry weight in mutant. ${ }^{37}$ The same wild-type strain of $A$. oryzae grown in a medium containing $5 \%$ xylose produced almost negligible amounts of xylanase and $\beta$-glucosidase; however, the mutant strain grown in the same medium in which creA had been deleted produced approximately 40 and $0.6 \mathrm{U} / \mathrm{g}$ dry weight. ${ }^{38}$ Therefore, creA can regulate the production of $\alpha$-amylase, xylanase, and $\beta$-glucosidase.

Although the presence of glucose in the medium inhibited the production of endo-xylanase and $\beta$-xylosidase, it did not affect the growth of all strains. The strains grew well on both media, whether such strains contained glucose or not, and even the strains grew better in medium containing glucose. Considering that glucose can be easily metabolized by the cells, organisms might grow rapidly in a medium containing simple sugar than xylan. Therefore, the weight of biomass grown in the glucose medium was higher than that grown in the xylan medium. The higher the glucose concentration in the culture medium, the faster the growth of fungi because of the availability of nutrients to support growth (Fig. 3). This result was consistent with another report, that is, increasing glucose concentration in the medium could increase fungal biomass. ${ }^{39}$

The $\mathrm{pH}$ of the medium after 4 days of incubation of all strains showed that the medium added with glucose was lower compared with the xylan medium only. Considering that fungi also produce acid in the metabolism pathway, glucose is easily converted into acid compared with xylan. Therefore, the higher the glucose concentration in the medium, the more depleted the $\mathrm{pH}$ medium (data not shown). Other research also reported that increasing glucose at a concentration of $1 \%-3 \%$ in the medium would decrease the $\mathrm{pH}$ in P. scabrosum. ${ }^{39}$

\section{CONCLUSION}

Among the strains examined, $A$. aculeatus FIG1 was the highest producer of endo-xylanase, and T. asperellum PK1J2 was the highest producer of $\beta$-xylosidase. The production of endo-xylanase and $\beta$-xylosidase was partially repressed in some strains and completely repressed in other strains when the strains were grown in a medium containing $1 \%$ glucose. However, the production of endo-xylanase and $\beta$-xylosidase was completely repressed when the strains were grown in a medium containing $3 \%$ glucose.

\section{ACKNOWLEDGMENTS}

The authors express their deep gratitude to the technical staffs at the Biotechnology Laboratory of Department of Food and Agricultural Product Technology, Faculty of Agricultural Technology, Universitas Gadjah Mada, Yogyakarta, Indonesia for their assistance in this work.

\section{CONFLICT OF INTEREST}

The authors declare that there is no conflict of interest.

\section{AUTHORS' CONTRIBUTION}

RK performed the experiment, analyzed the data, and drafted the original manuscript. MNC, SJN, JW, DAS supervised and conceptualized the methodology, edited and reviewed the manuscript. All authors have read this manuscript and agreed to be published.

\section{FUNDING}

This study was supported by the Ministry of Research, Technology/National Research, and Innovation Agency of Republic Indonesia (RISTEKBRIN) through research grants of PMDSU Batch III 
scholarship by letter number: 5715/UN1.DITLIT/ DIT-LIT/LT/2018.

\section{DATA AVAILABILITY}

All datasets generated or analyzed during this study are included in the manuscript.

\section{ETHICS STATEMENT}

This article does not contain any studies with human participants or animals performed by any of the authors.

\section{REFERENCES}

1. Kumar D, Kumar SS, Kumar J, et al. Xylanases and their industrial applications: A review. Biochem Cell Arch. 2017;17(1):353-360.

2. Goswani GK, Rawat S. Microbial xylanase and their applications. Int J Curr Res Acad Rev. 2015;3(6):436450.

3. Sathish T, Murthy NYS. Optimisation of xylose production using xylanase. Int J Chem Sci. 2010;8(2):909-913.

4. Butt MS, Tahir-Nadeem M, Ahmad Z, Sultan MT. Xylanases and their applications in baking industry. Food Technol Biotechnol. 2008;46(1):22-31.

5. Mikus L, Dodok L, Kovacova M, Staruch L, Koman V. Bakery enzymes in cereal technologies. Potravinarstvo. 2012;6(3):10-15. doi: 10.5219/193

6. Viniegra-Gonzalez G, Favela-Torres E, Noe Aguilar C, Romero-Gomez SDJ, Gerardo D-G, Augur C. Advantages of fungal enzyme production in solid state over liquid fermentation systems. Biochem Eng J. 2003;13(23):157-167. doi: 10.1016/S1369-703X(02)00128-6

7. Juturu V, Wu JC. Microbial xylanases: Engineering, production and industrial applications. Biotechnol Adv. 2012;30(6):1219-1227. doi: $10.1016 / \mathrm{j}$. biotechadv.2011.11.006

8. Polizeli MLTM, Rizzatti ACS, Monti R, Terenzi HF, Jorge JA, Amorim DS. Xylanases from fungi: Properties and industrial applications. Appl Microbiol Biotechnol. 2005;67(5):577-591. doi: 10.1007/s00253-005-1904-7

9. Shimokawa T, Yamaguchi M, Shibuya H, et al. Screening of lignocellulolytic enzyme producers: Enzyme system from Aspergillus tubingensis for hydrolysis of sugi pulp. Bull FFPRI. 2012;11(2):57-63.

10. Ja'afaru MI. Screening of fungi isolated from environmental samples for xylanase and cellulase production. ISRN Microbiol. 2013;2013:283423. doi: 10.1155/2013/283423

11. Marques NP, de Cassia Pereira J, Gomes E, et al. Cellulases and xylanases production by endophytic fungi by solid state fermentation using lignocellulosic substrates and enzymatic saccharification of pretreated sugarcane bagasse. Ind Crops Prod. 2018;122:66-75. doi: 10.1016/j.indcrop.2018.05.022

12. Deutscher J. The mechanisms of carbon catabolite repression in bacteria. Curr Opin Microbiol. 2008;11(2):87-93. doi: 10.1016/j.mib.2008.02.007

13. Carrillo-Sancen G, Carrasco-Navarro U, Tomasini-
Campocosio A, Corzo G, Pedraza-Escalona MM, Favela-Torres E. Effect of glucose as a carbon repressor on the extracellular proteome of Aspergillus niger during the production of amylases by solid state cultivation. Process Biochem. 2016;51(12):2001-2010. doi: 10.1016/j.procbio.2016.09.001

14. Solis-Pereira S, Favela-Torres E, Viniegra-Gonzalez G, Gutierrez-Rojas M. Effects of different carbon sources on the synthesis of pectinase by Aspergillus niger in submerged and solid state fermentations. Appl Microbiol Biotechnol. 1993;39(1):36-41. doi: 10.1007/ BF00166845

15. Aguilar CN, Augur C, Favela-Torres E, Viniegra-Gonzalez G. Production of tannase by Aspergillus niger Aa-20 in submerged and solid-state fermentation: Influence of glucose and tannic acid. J Ind Microbiol Biotechnol. 2001;26(5):296-302. doi: 10.1038/sj.jim.7000132

16. Mandels $M$, Reese ET. Induction of cellulase in Trichoderma viride as influenced by carbon sources and metals. J Bacteriol. 1957;73(2):269-278. doi: 10.1128/jb.73.2.269-278.1957

17. Chand P, Aruna A, Maqsood AM, Rao LV. Novel mutation method for increased cellulase production. J Appl Microbiol. 2005;98(2):318-323. doi: 10.1111/j.13652672.2004.02453.x

18. Kundu A, Rani R. Production of intracellular $\beta$-xylosidase from the submerged fermentation of citrus wastes by Penicillium janthinellum MTCC 10889. 3 Biotech. 2013;3:241-246. doi: 10.1007/s13205-012-0091-3

19. Sakthiselvan P, Naveena B, Partha N. Molecular characterization of a Xylanase-producing fungus isolated from fouled soil. Braz J Microbiol. 2014;45(4):1293-1302. doi: 10.1590/S151783822014000400020

20. Kiss T, Kiss L. Purification and characterization of an extracellular-xylosidase from Aspergillus carbonarius. World J Microbiol Biotechnol. 2000;16:465-470. doi: 10.1023/A:1008912025896

21. Benassi VM, de Lucas RC, Jorge JA, Polizeli MLTM. Screening of thermotolerant and thermophilic fungi aiming $\beta$-xylosidase and arabinanase production. Braz J Microbiol. 2014;45(4):1459-1467. doi: 10.1590/ S1517-83822014000400042

22. Ajijolakewu KA, Leh CP, Lee CK, Wan Nadiah WA. Characterization of novel Trichoderma hemicellulase and its use to enhance downstream processing of lignocellulosic biomass to simple fermentable sugars. Biocatal Agric Biotechnol. 2017;11:166-175. doi: 10.1016/j.bcab.2017.06.005

23. Pinaga F, Fernandez-Espinar MT, Valles S, Ramon D. Xylanase production in Aspergillus nidulans: Induction and carbon catabolite repression. FEMS Microbiol Lett. 1994;115:319-323. doi: 10.1111/j.1574-6968.1994. tb06657.x

24. De Vargas Andrade S, De Moraes MD, Terenzi HF, Jorge JA. Effect of carbon source on the biochemical properties of xylosidases produced by Aspergillus versicolor. Process Biochem. 2004;39(12):1931-1938. doi: 10.1016/j.procbio.2003.09.024

25. Flores ME, Perea M, Rodriguez O, Malvaez A, Huitron $C$. Physiological studies on induction and catabolite repression of $\beta$-xylosidase and endoxylanase in 
Streptomyces CH-M-1035. J Biotechnol. 1996;49:179187. doi: 10.1016/0168-1656(96)01542-8

26. Forsan $C F$, de Freitas $C$, Masarin F, Brienzo M Xylooligosaccharide production from sugarcane bagasse and leaf using Aspergillus versicolor endoxylanase and diluted acid. Biomass Convers Biorefinery. 2021;26:1-17. doi: 10.1007/s13399-02101403-2

27. Heinen PR, Pereira MG, Rechia CGV, et al. Immobilized endo-xylanase of Aspergillus tamarii Kita: An interesting biological tool for production of xylooligosaccharides at high temperatures. Process Biochem. 2017;53:145152. doi: 10.1016/j.procbio.2016.11.021

28. Palaniappan A, Antony U, Emmambux MN. Current status of xylooligosaccharides: Production, characterization, health benefits and food application. Trends Food Sci Technol. 2021;111:506-519. doi: 10.1016/j.tifs.2021.02.047

29. Avila PF, Martins M, de Almeida Costa FA, Goldbeck R. Xylooligosaccharides production by commercial enzyme mixture from agricultural wastes and their prebiotic and antioxidant potential. Bioact Carbohydrates Diet Fibre. 2020;24:100234. doi: 10.1016/j.bcdf.2020.100234

30. Naidu DS, Hlangothi SP, John MJ. Bio-based products from xylan: A review. Carbohydr Polym. 2018;179:2841. doi: 10.1016/j.carbpol.2017.09.064

31. Motta FL, Andrade CCP, Santana MHA. A review of xylanase production by the fermentation of xylan: Classification, characterization and applications. Sustain Degrad Lignocellul Biomass - Tech Appl Commer. 2013:251-275.

32. Ang SK, Shaza EM, Adibah YA, Suraini AA, Madihah MS. Production of cellulases and xylanase by Aspergillus fumigatus SK1 using untreated oil palm trunk through solid state fermentation. Process
Biochem. 2013;48(9):1293-1302. doi: 10.1016/j. procbio.2013.06.019

33. Tirado-Gonzalez DN, Jauregui-Rincon J, TiradoEstrada GG, Martinez-Hernandez PA, Guevara-Lara F, Miranda-Romero LA. Production of cellulases and xylanases by white-rot fungi cultured in corn stover media for ruminant feed applications. Anim Feed Sci Technol. 2016;221(Part A):147-156. doi: 10.1016/j. anifeedsci.2016.09.001

34. Adnan M, Zheng W, Islam W, et al. Carbon catabolite repression in filamentous fungi. Int J Mol Sci. 2018;19(1):48. doi: 10.3390/ijms19010048

35. Tanaka M, Gomi K. Induction and repression of hydrolase genes in Aspergillus oryzae. Front Microbiol. 2021;12:1-10. doi: 10.3389/fmicb.2021.677603

36. Sun J, Glass NL. Identification of the CRE-1 cellulolytic regulon in Neurospora crassa. PLoS One. 2011;6(9):e25654. doi: 10.1371/journal.pone.0025654

37. Ichinose S, Tanaka M, Shintani T, Gomi K. Improved $\alpha$-amylase production by Aspergillus oryzae after a double deletion of genes involved in carbon catabolite repression. Appl Microbiol Biotechnol. 2014;89:335343. doi: 10.1007/s00253-013-5353-4

38. Ichinose S, Tanaka M, Shintani T, Gomi K. Increased production of biomass-degrading enzymes by double deletion of creA and creB genes involved in carbon catabolite repression in Aspergillus oryzae. J Biosci Bioeng. 2018;125(2):141-147. doi: 10.1016/j. jbiosc.2017.08.019

39. Barborakova Z, Labuda R, Haubl G, Tancinova D. Effect of glucose concentration and growth conditions on the fungal biomass, $\mathrm{pH}$ of media and production of Fumagillin by a non-pathogenic strain Penicillium scabrosum. J Microbiol Biotechnol Food Sci. 2012;1(4):466-476. 